\title{
Tohum kaplama makinası kazan çapının marul (Lactuca sativa L.) tohumunda bazı kaplama kriterlerine etkisi
}

\section{Effect of hopper diameter of seed coating machine on some coating criteria in lettuce (Lactuca sativa L.) seed}

\author{
Ahmet Fatih HACIYUSUFOĞLU(i) \\ Aydın Adnan Menderes Üniversitesi, Aydın Meslek Yüksekokulu, Aydın \\ Sorumlu yazar (Corresponding author): A. F. Hacıyusufoğlu, e-posta (e-mail): afatih@adu.edu.tr
}

\section{MAKALE BILLGISİ}

Alınış tarihi 25 Mart 2020

Düzeltilme tarihi 04 Temmuz 2020

Kabul tarihi 09 Temmuz 2020

\section{Anahtar Kelimeler:}

Pelet tohum kaplama

Marul tohumu

Kaplama kalitesi

\begin{abstract}
ÖZ
Bitkisel üretimde başarılı bir tohum/fide olușturulmasında; genetik özelliklerin yanında, optimum çimlenme faktörlerinin de ortaya konulması gerekmektedir. Bu çalışma da duna cinsi marul tohumlarına, iki farklı çapa sahip $(450-600 \mathrm{~mm})$ dikey rotorlu peletle tohum kaplama makinası ile pelet kaplama uygulanmıştır. Böylece farklı çaptaki dikey rotorların, kaplama kalite kriterlerine etkisi ortaya konulmaya çalışılmıştır. Küresellik, geometrik ortalama çap tohumların ekilișlerinde önemli etkenlerdendir. Rotor çapı $450 \mathrm{~mm}$ olan makine ile kaplamanın, $600 \mathrm{~mm}$ çapa sahip olan kaplamaya göre küresellik (0.79-0.76) ve geometrik ortalama çap (2.95-2.82) değerleri bakımından daha olumlu sonuç verdiği ortaya konulmuştur. Fide yetiștiriciliği açısından önemli bir kriter olan tek taneli pelet elde etme yönünden, $\mathrm{Kapl}^{450}$ grubunda tek tohum oran1 $\% 97$ olurken, Kapl1 ${ }^{600}$ grubunda ise tek tohum oran1 \%92 olmuştur. Çimlenme oranı bakımından \%4'lük fark ile Kapl1 ${ }^{450}$ grubunun çimlenme oranlar değerleri (\%70.25) daha yüksek değere sahip olmuştur. Tüm bu veriler incelendiğinde küçük çaplı olan marul tohumlarının peletle kaplanmasında $600 \mathrm{~mm}$ yerine $450 \mathrm{~mm}$ olan daha küçük rotor çapına sahip olan makine ile kaplama; tek tohum oluşması, geometrik çap ve küresellik kriterleri açısından daha olumlu sonuçlar ortaya koymaktadır.
\end{abstract}

\section{ARTICLE INFO}

Received 25 March 2020

Received in revised form 04 July 2020

Accepted 09 July 2020

\section{Keywords:}

Seed Pelleting

Lettuce Seed

Coating Quality

\begin{abstract}
Obtaining a successful seed/seedling in plant cultivation is contingent on not only genetic characteristics but also ensuring optimum germination factors. In this study, pellet coating was applied on duna lettuce seeds using a seed pelleting machine having vertical rotors with two different diameters $(450$ and $600 \mathrm{~mm}$ ). Thus, the study tried to show the effect of vertical rotors with different diameters on the quality criteria of coating. Sphericity and geometric mean diameter are among the important factors in sowing seeds. It was shown that the coating performed using the rotor diameter of $450 \mathrm{~mm}$ yielded more favorable results than the coating done with the rotor diameter of $600 \mathrm{~mm}$ in terms of sphericity ( 0.79 vs. 0.76$)$ and geometric mean diameter ( 2.95 vs. 2.82 ). As to obtaining individually pelleted seeds, which is a significant criterion in seedling cultivation, the rate of individually pelleted seeds was $97 \%$ in the Coated ${ }^{450}$ group versus $92 \%$ in the Coated ${ }^{600}$ group. The germination rate of the Coated ${ }^{450}$ group $(70.25 \%)$ was found to be higher with a difference of $4 \%$ in terms of seedling cultivation. In the light of all these data, it was found that using a pelleting machine having a smaller rotor diameter of $450 \mathrm{~mm}$ instead of $600 \mathrm{~mm}$ to pellet lettuce seeds of smaller diameters yielded more favorable results in terms of individually pelleted seed, geometric diameter and sphericity criteria.
\end{abstract}

\section{Giriş}

Tarımsal üretimde tohum, yetiştiriciliğin ilk adımıdır. Özellikle bazı hibrid sebze ve süs bitkileri tohumları ticari olarak değerli konuma geçmişlerdir. Tohumun ilk çıkış gücü bitki standı oluşturmada önemli bir faktördür ve sağlıklı gerçekleşmesi verime olumlu etki etmektedir. Sebzecilikte hibrid tohumlarının maliyetlerinin yüksek ve tek dane ekimde bazı olumsuzlukların olmasindan dolayı peletle tohum kaplama alanına yönelmeyi zorunlu kılmaktadır. Tohum kaplama malzemelerinin çimlenmeyi iyileştirmesinin yanında düşük toprak nem rejiminde fidelerin çıkışını iyileştirdiği 
bilinmektedir (Sherin 2003). Islah çalışmaları açısından kaplanmış tohum kullanımı ise özellikle nitelikli tohum materyalinden daha sağlıklı bitki elde edilmesi ve bu bitkilerin ıslah çalışmalarında kullanımına imkân vermesi önemli bir parametredir (Sarıçam ve ark. 2018).

Genel olarak tohum peletleme; ekilebilirlik, verim ve çimlenme performansı artırmak için tohuma uygulanan yöntemdir. Tohum kaplamada bitki besin elementleri, fungusitler, insektisitler, herbisitler ve yararlı organizmalardan yararlanılmaktadır (Gerber 1988; Nascimento ve ark. 1993; Taylor ve ark. 1998; Barut 2006; Rufino ve ark. 2013; Corlett ve ark. 2014; Haciyusufoglu ve Erkul 2015). Tohum peletleme; küçük, hafif ve şekilsiz tohumların makineli ekime uygun hale getirilmesi için katı partiküllerin tohumun etrafına sardırılması işlemidir. Peletlemede tohumun şeklini ve boyutunu değiştirmek için tohumun daha ağır ve yuvarlak olması için kaplama malzemeleri kullanılmaktadır. Pelet tohum ile bir tohumun esas şeklini gizleme yeteneği ile karakterize edilir ve aynı zamanda tohumun fiziksel modifikasyonu, tohum ağırlığ ve büyüklüğünün standardizasyonu yoluyla tohumun iyileştirilmesini amaçlamaktadır (Copeland ve McDonald 1995; Halmer 2006). Ancak tohum kalitesinin korunması gereklidir ve çimlenmeye engel olmamalıdır. $\mathrm{Bu}$ yüzden topaklanma materyalleri tohumlar ile uyumlu olması gerekir.

Peletleme kaplamanın asıl amacı; tohumların çaplarının büyütülmesi ve tohumlara şekilsel olarak küresel yapıyı kazandırmaktır. Bu tip tohum kaplama teknolojilerinin temel hedefi, kaplama işlemi sırasında tohum kaplama materyallerini tohum yüzeyine üniform bir şekilde uygulamaktır (Kavak 2006, Sikhoa ve ark. 2015).

Tohum kaplama kalitesine etki eden unsurlar; tohum kaplama maddesinin içeriği, kaplamada kullanılan yapıştırma maddesi, çıplak tohum boyutu, kaplı tohum boyutu, tohumların şekli, tohumların su çekme yeteneği, kullanılan kaplama makinasının özellikleri, kaplama makinası kazanının devir sayısı ve tohum kaplama işlemini yapanın bilgi ve tecrübesidir (Haciyusufoğlu 2013)

Kaplanmış tohumların kalite kriterleri ise şu şekildedir (Hacıyusufoğlu 2013);

- Tohumların çimlenme gücü

- Tohumların canlılık oranı

- Stres koşullarına dayanım

- Her pelette boş, tek ya da birden fazla tohum bulunması

- Tohum boyutunun homojenliği

- Oluşan pelet tohumların sertliği

- Tohumların suda çözünme süresi

- Tohumların çimlenme esnasında küflenme vb. patojenlere gösterdiği tepki

- Tohumların yüzey pürüzlülüğü

- Tohumların çimlenme gücünü koruyabilmesi

- Tohumların tek dane ekim makinaları ile ekilebilmeye uyumluluğu

Marul (Lactuca sativa L.) tohumları çok küçük olup 1000 tane ağırlığı yaklaşık 0.9 g'dır. Bu yüzden ticari marul tohumları kaplanmış olarak satılmaktadır (Sarıçam ve ark. 2018).

Bu çalışmada; duna çeşidi marul tohumları 450 ve $600 \mathrm{~mm}$ çaplarında kazan çapına sahip tohum kaplama makinalarında pelet kaplama uygulaması yapılarak, uygulama sonrasında bazı tohumluk kriterlerine etkilerinin karşılaştırılması yapılmıştır.

\section{Materyal ve Yöntem}

Denemelerde tohum kaplama için, dikey eksenli $450 \mathrm{~mm}$ ve $600 \mathrm{~mm}$ çaplı kazana sahip tohum kaplama makinaları kullanılmıştır (Şekil 1). Makina rotoru gücünü $220 \mathrm{~V}$ $1.5 \mathrm{~kW}$ 'lık elektrik motorundan almaktadır. Rotor devir hızı, hız kontrol cihazı sayesinde $0-1500 \mathrm{~min}^{-1}$ aralığında değiştirilebilmektedir. Döner rotorun orta kısmından sı1v1 dağıtıcı elemana serbest halde sıvı materyal bırakılmaktadır. Tohum kaplama tozu ise makine operatörü tarafindan tohumların üzerine serbest halde uygun miktarda ölçülü kap vasitasiyla verilmektedir.

Denemeler 2 farklı çapa sahip makine ile marul tohumlarının kaplanması ile laboratuvar ortamında 4 tekerrürlü olarak gerçekleştirilmiştir. Marul tohumları 1/20 oranında (1 kg tohuma $20 \mathrm{~kg}$ tohum kaplama tozu) Kwizda marka 2 numaral hazır tohum kaplama tozu ile kaplanarak çapları büyütülmüştür (Şekil 2). Kaplanan tohumlara $32^{\circ} \mathrm{C}$ sicaklığa sahip hava verilerek kurutulmaya bırakılmıştır. Daha sonra kurutulan tohumların laboratuvar ortamında bazı fiziko-mekanik özellik ve çimlenme parametreleri bakımından ölçümleri yapılmıştır. Kaplama esnasında kronometre ile kaplama süresi takip edilmiştir. Tohumların aynı oranda kaplama preparatı ile kaplanması esnasında 8 dakikalık eşit kaplama süresi göz önüne alınarak kaplamalar gerçekleştirilmiştir.

Tohumların kaplama öncesi ve kaplama sonrasında bin dane ağırlıkları genişlik, boy ve kalınlık ölçümleri yapılmış, geometrik ortalama çapları ve küresellikleri hesaplanmıştır.

Tohumların geometrik ortalama çapları $\left(\mathrm{d}_{\mathrm{g}}\right)$ ve küresellikleri ( $\phi) 1$ ve 2 numaralı formüllerden yararlanılarak hesaplanmıştır; (Mohsenin 1978; Aydın 2003; Olajide ve Igbeka 2003; Coşkun ve ark. 2006; Yalçın ve ark. 2007). Formüllerde; L uzunluk $(\mathrm{mm})$; W, genişlik $(\mathrm{mm})$ ve $\mathrm{T}$ ise kalınlığı (mm) ifade etmektedir.

$d_{g}=(L W T)^{1 / 3}$

$\phi=\frac{(L W T)^{1 / 3}}{L}$

Tohum kaplamada her bir kaplı tohumda tek tohumun olması istenmektedir. Oluşturulan pelet içerisinde hiç tohum olmaması ya da birden fazla olması tohumculuk ve bitki yetiştiriciliği bakımından olumsuzluklar ortaya çıkarmaktadır. $\mathrm{Bu}$ sebeple kaplanmış tohumlar, 3 tekerrür olarak 100'er adet kırılarak içindeki tek, boş ve çift taneli tohumların sayımları yapılmışıır. Genellikle boş tohumların şekilleri daha küresel, dolu tohumlar ise oval bir yapıya sahip oldukları tespit edilmiştir.

Laboratuvar koşullarında iklim dolabındaki çimlendirme testleri, 4 tekerrürden oluşan (her tekerrürde 100 tohum) toplam 400 tohumla yapılmıştır. Çimlendirme testlerinde kaplı olmayan tohumlar standart filtre kâğıtları üzerine koyulmuş ve ISTA normları esas alınarak $+20^{\circ} \mathrm{C}$ 'de $10 \mathrm{cc}$ su ile 4., 7. ve 10 . gün sayımları yapılarak bazı çimlenme parametreleri elde edilmiştir (ISTA 2013). Kaplı tohumlar ise kaplı tohumlar için özel üretilmiş çimlenme kâğıtlarında yine 4 tekerrürlü olarak $20^{\circ} \mathrm{C}$ 'de $10 \mathrm{cc}$ su ile 4 ., 7. ve 10 . gün sayımları yapılarak bazı çimlenme parametreleri elde edilmiştir (Şekil 3). Kökçük uzunluğu $5 \mathrm{~mm}$ olan tohumlar çimlenmiş olarak kabul edilmiş ve çimlendirme ortamının ihtiyacına göre sulama yapılmıştır. 
Çıkış hızı (ÇH) ve çıkış oranı (ÇO) 3 ve 4 numaralı eşitliklerden yararlanarak bulunmuştur (Yıldız ve Özgen, 2004). Hesaplamalar yapılırken her petri kabındaki sayımlardan elde edilen değerlerin her biri ayrı ayrı formüllere uygulanmış, daha sonra elde edilen değerlerin ortalamaları hesaplanmıştır. Bulunan değerler istatistiki olarak değerlendirilmiştir.

$$
C ̧ H=\frac{\sum n i}{\sum n} i
$$

ÇH (gün): Çıkış hızı, ni: $i$. gündeki çimlenen sayısı, i: sayımın yapıldığı gün, $n$ : petri kabında çimlenen toplam tohum say1s1.

$$
C \zeta O=\frac{\sum n i}{N} x 100
$$

$C ̧ O$ (\%): Çıkış oranı, ni: i. gündeki çimlenen sayısı, $N$ : Teste konulan toplam tohum sayıs1.

Elde edilen verilerin normal dağılıșa uygunluğunu test etmek için SAS (1999) istatistik paket programında yer alan UNIVARIATE prosedürü kullanılmıştır. Normal dağılışa uygunluğu tespit edilen özelliklerin en küçük kareler ortalamaları ve standart hatalarının hesaplanmasında SAS (1999) istatistik paket programında yer alan GLM prosedürü kullanılmıştır. Ortalamalar arasındaki farklılı̆̆ın ortaya konması için Duncan çoklu karşılaştırma testi kullanılmıştır.
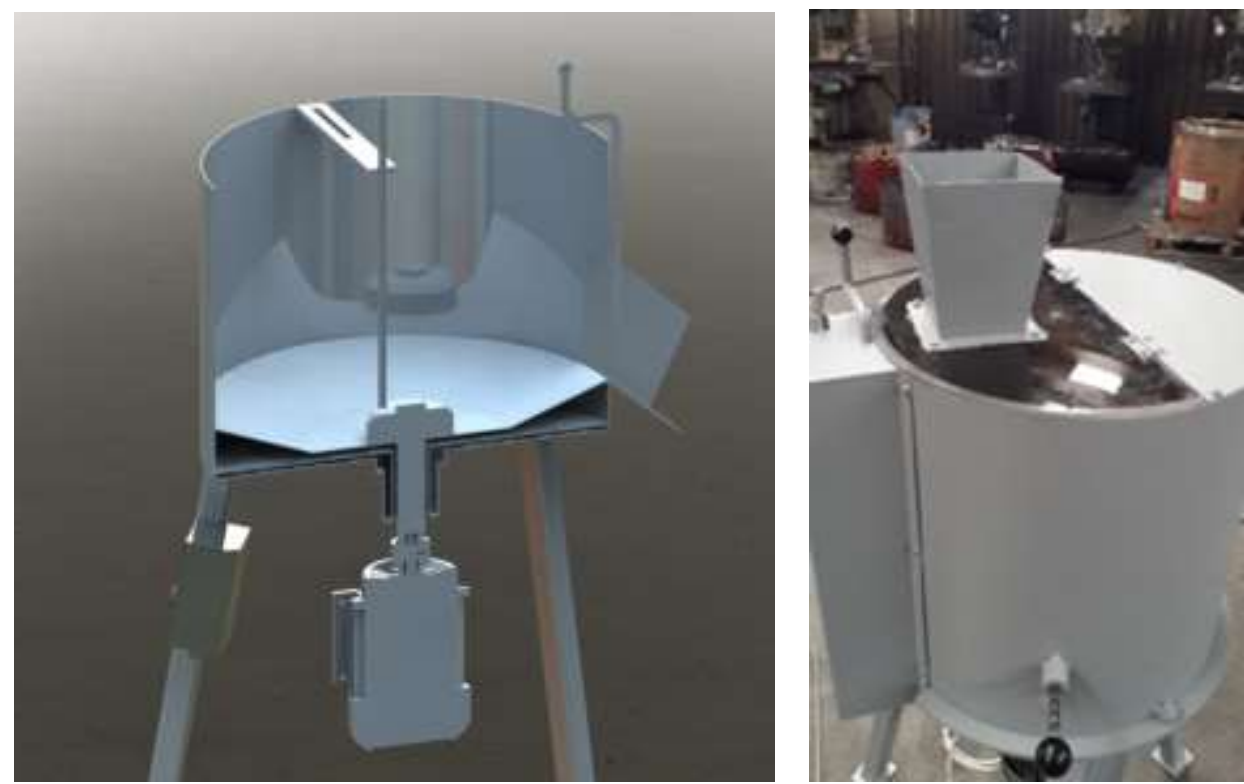

Şekil 1. Tohum kaplama makinası ana elemanları ve makine (1-kazan, 2-döner rotor, 3- hız kontrol cihazı, 4-elektrik motoru).

Figure 1. Seed coating machine main elements and machine (1-batch, 2-rotary rotor, 3-speed controller, 4-electric motor).

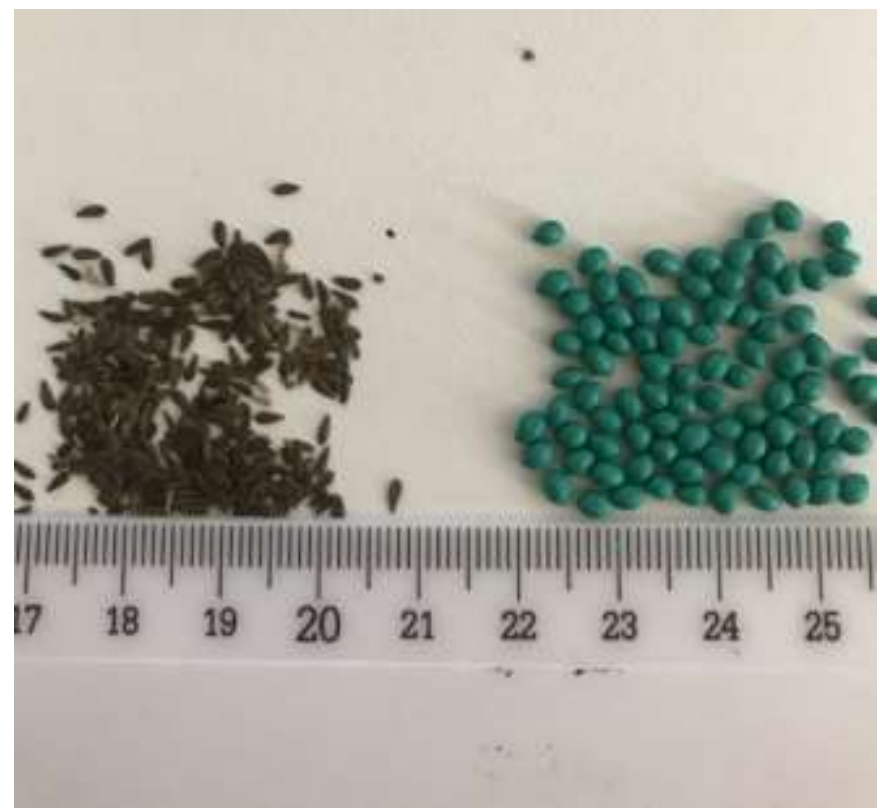

Şekil 2. Kaplı olmayan ve peletle kaplı tohumlar.

Figure 2. Uncoated and pelleted seeds. 


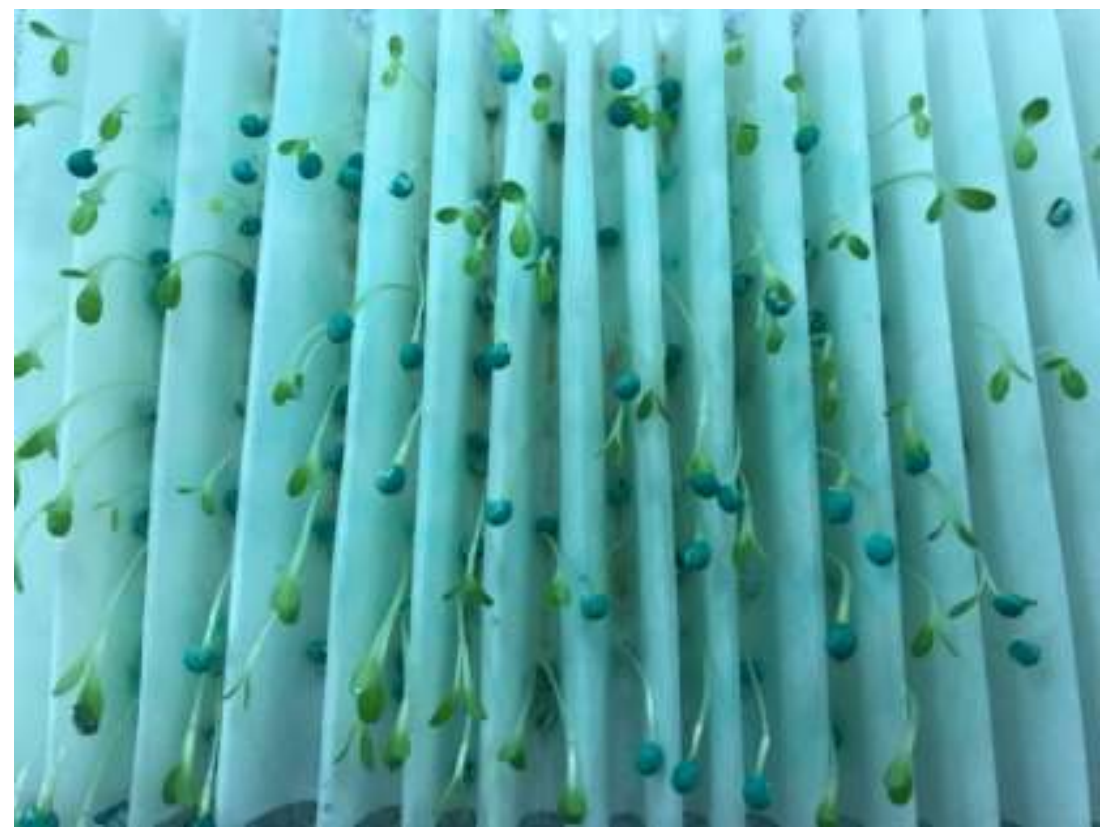

Şekil 3. Kaplı tohumların çimlenmesi.

Figure 3. Germination of pelleted seeds.

\section{Bulgular ve Tartışma}

Çalışmada elde edilen bulgularda Kontrol, kaplı olmayan marul tohumunu; $\mathrm{Kapl}_{1}{ }^{450}$, $450 \mathrm{~mm}$ kazan çapında kaplanan tohumu; Kaplı ${ }^{600}$, $600 \mathrm{~mm}$ kazan çapında kaplanan tohumu; ÇH ort, ortalama çıkış hızını; ÇOort, ortalama çıkış oranını ifade etmektedir.

Marul tohumlarına ait bazı fiziko-mekanik özelliklerden bin dane ağırlığı $(\mathrm{g})$, geometrik ortalama çap $(\mathrm{mm})$ ve küresellik değerleri Çizelge 1'de verilmiştir. Çizelge 1 'de Kapl1 ${ }^{450}$ grubu ile $\mathrm{Kapl}^{600}$ grubunun aynı miktarda kaplama tozu ile kaplandığ halde bin dane ağırlıklarında fark oluşmasının temel nedeni; kaplama esnasında ilk sardırma işlemi sonrası oluşan boş tohumların temizlenmesi amacı ile eleme yapılmış olmasıdır. $\mathrm{Bu}$ elemenin yapılmadığı durumlarda kaplama sonunda çok daha fazla oranda içi boş pelet oluşmasına neden olmakta ve kaplama kalitesini olumsuz etkilemektedir. $450 \mathrm{~mm}$ çapındaki makine ile kaplamalarda elde edilen tohumların küresellik değerleri (0.79) ekim makinası ile ekime daha uygun olduğu söylenebilir.

Çizelge 1. Bazı fiziko-mekanik özellikler ortalama değerleri.

Table 1. Some physico-mechanical properties average values.

\begin{tabular}{cccc}
\hline $\begin{array}{c}\text { Tohum } \\
\text { Çeşidi }\end{array}$ & $\begin{array}{c}\text { Bin dane } \\
\text { Ağırlığı } \mathbf{( g )}\end{array}$ & $\begin{array}{c}\text { Geometrik Çap } \\
(\mathbf{m m})\end{array}$ & Küresellik \\
\hline Kontrol & $0.79 \pm 0.024$ & $1.27 \pm 0.067$ & $0.37 \pm 0.064$ \\
Kaplı $^{450}$ & $15.96 \pm 0.051$ & $2.95 \pm 0.093$ & $0.79 \pm 0.042$ \\
Kaplı $^{600}$ & $15.47 \pm 0.036$ & $2.83 \pm 0.180$ & $0.77 \pm 0.042$ \\
\hline
\end{tabular}

Kaplı tohumların suda çözünme süresi, tohumların çimlenme parametrelerine etki etmektedir. Suda çözünme süresi düşük olan kaplı tohumlar genellikle daha yüksek çimlenme oranı ve çimlenme hızına sahip olmaktadırlar. Tohumların suda çözünme süresi ortalama 52 saniye olmuştur. Fesleğen tohumuna peletle kaplama uygulamas1 yapan Karakuzu (2015), tohumların suda çözünme süresini 7.8 saniye olarak bulmuştur. Çözünme süresindeki farklılığın temel nedeni, kaplama materyallerinin içerikleridir.

Marul tohumlarında pelet kaplamanın tohum boyutlarına etkisi Çizelge 2'de, tohumların uzunluk, genişlik, kalınlık ortalamaları ise Çizelge 3'te verilmiştir. Çizelge 3'te kaplı tohumların uzunlukları arasında istatistiki olarak fark bulunmadığı, genişlik ve kalınlıkları arasında ise farkın olduğu görülmektedir. Kaplı olmayan tohumların boyutları ise farklı bir grupta yer almaktadır.

Çizelge 4'de görüldüğü gibi $\mathrm{Kapl}^{450}$ grubu tohumlarda $\% 97$, Kapl1 ${ }^{600}$ grubunda ise $\% 92$ oranında tek tohum oluşmuştur. Tohum kaplama kalite kriterleri açısından her pelette tek tohum oluşması, fide yetiştiriciliği açısından önemli ve tercih edilen bir kriterdir. Bu bakımdan Kapl1 ${ }^{450}$ grubundaki \%97'lik oran daha başarılı bir kaplama olduğunun göstergesidir.

Çizelge 5'teki analizi sonuçlarına bakıldığında kontrol ve farklı çaplardaki kazan çapı ile kaplanmış tohumların çimlenme oranlarına etkisinin önemli olduğu görülmektedir $(\mathrm{p}<0.05)$. $\mathrm{Kapl}^{450}$ grubu tohumlarla Kapl1 ${ }^{600}$ grubu tohumların çimlenme oranları ise aynı grupta yer almıştır. Kontrol ve Kapl ${ }^{600}$ grubu tohumların çimlenme hızlarına etkisinin önemli olmadığı görülmektedir $(\mathrm{p}<0.05)$. Kapl1 ${ }^{450}$ grubu tohumlar ise farklı bir grupta yer almaktadır. Kapl1 ${ }^{450}$ grubu tohumların çimlenme hızı değerlerinin diğer gruplara göre farklılık göstermesinin temel nedeni, daha fazla kaplama tozu materyalinin israf edilmeden tohumlara sardırılabilmesi ve daha büyük boyutlarda kaplı tohum elde edilmesidir. Daha büyük boyutta olan pelet kaplı tohumların çıkış hızları değerleri yükselmekte ve dolayısıyla daha geç sürede çimlenmektedirler. 
Çizelge 2. Pelet kaplamanın tohum boyutlarına etkisi.

Table 2. Effect of pellet coating on seed sizes.

\begin{tabular}{|c|c|c|c|c|c|c|}
\hline Değişken & Yöntem & $\mathbf{N}$ & Ort \pm SS & VK $(\%)$ & Minimum (mm) & $\operatorname{Maximum}(\mathbf{m m})$ \\
\hline \multirow{3}{*}{ Uzunluk } & Kontrol & 21 & $3.46 \pm 0.293$ & 8.48 & 2.87 & 3.95 \\
\hline & Kapli $^{450}$ & 21 & $3.70 \pm 0.137$ & 3.71 & 3.42 & 3.91 \\
\hline & Kapl1 $^{600}$ & 21 & $3.67 \pm 0.180$ & 4.90 & 3.42 & 3.92 \\
\hline \multirow{3}{*}{ Genişlik } & Kontrol & 21 & $1.17 \pm 0.081$ & 6.95 & 1.02 & 1.29 \\
\hline & $\mathrm{Kapl1}^{450}$ & 21 & $2.68 \pm 0.200$ & 7.44 & 2.11 & 2.96 \\
\hline & Kapl1 $^{600}$ & 21 & $2.54 \pm 0.221$ & 8.70 & 2.16 & 2.88 \\
\hline \multirow{3}{*}{ Kalınlık } & Kontrol & 21 & $0.51 \pm 0.051$ & 9.93 & 0.43 & 0.64 \\
\hline & $\mathrm{Kapl1}^{450}$ & 21 & $2.60 \pm 0.185$ & 7.11 & 2.05 & 2.88 \\
\hline & Kapli $^{600}$ & 21 & $2.43 \pm 0.231$ & 9.50 & 2.01 & 2.79 \\
\hline
\end{tabular}

Çizelge 3. Tohumların uzunluk, genişlik ve kalınlık özelliklerine ilişkin en küçük kareler ortalamaları ve standart hataları.

Table 3. Minimum squares averages and standard errors regarding the length, width and thickness characteristics of the seeds.

\begin{tabular}{cccc}
\hline & Uzunluk $(\mathbf{m m})$ & Genişlik $(\mathbf{m m})$ & Kalınlık $(\mathbf{m m})$ \\
\cline { 2 - 4 } Yöntem & $\mathbf{P}=\mathbf{0 . 0 0 1}$ & $\mathbf{P}=\mathbf{0 . 0 0 0}$ & $\mathbf{P}=\mathbf{0 . 0 0 0}$ \\
\hline Kontrol & $3.46 \pm 0.047^{\mathrm{a}}$ & $1.17 \pm 0.039^{\mathrm{a}}$ & $0.51 \pm 0.038^{\mathrm{a}}$ \\
Kapl1 $^{450}$ & $3.70 \pm 0.047^{\mathrm{b}}$ & $2.68 \pm 0.039^{\mathrm{b}}$ & $2.60 \pm 0.038^{\mathrm{b}}$ \\
Kapl1 $^{600}$ & $3.67 \pm 0.047^{\mathrm{b}}$ & $2.54 \pm 0.039^{\mathrm{c}}$ & $2.43 \pm 0.038^{\mathrm{c}}$ \\
\hline Genel & $\mathbf{3 . 6 1} \pm \mathbf{0 . 0 2 7}$ & $\mathbf{2 . 1 3} \pm \mathbf{0 . 0 2 2}$ & $\mathbf{1 . 8 5} \pm \mathbf{0 . 0 2 2}$ \\
\hline
\end{tabular}

Çizelge 4. Kaplı marul tohumlarının doluluk oranları.

Table 4. Occupancy rates of covered lettuce seeds.

\begin{tabular}{cccc}
\hline & Tek Tohum & Boş Tohum & Çift Tohum \\
\cline { 2 - 4 } Yöntem & $\mathbf{P}=\mathbf{0 . 0 1 8}$ & $\mathbf{P}=\mathbf{0 . 0 2 1}$ & $\mathbf{P}=\mathbf{0 . 0 2 6}$ \\
\hline $400 \mathrm{~mm}$ & $97.00 \pm 0.913$ & $2.00 \pm 0.577$ & $1.00 \pm 0.408$ \\
$600 \mathrm{~mm}$ & $92.00 \pm 0.913$ & $5.00 \pm 0.577$ & $3.00 \pm 0.408$ \\
\hline Genel & $\mathbf{9 4 . 5 0} \pm \mathbf{0 . 6 4 5}$ & $\mathbf{3 . 5 0} \pm \mathbf{0 . 4 0 8}$ & $\mathbf{2 . 0 0} \pm \mathbf{0 . 2 8 9}$ \\
\hline
\end{tabular}

Çizelge 5. Farklı çapta kazan ile kaplamanın marul tohumunda çıkış (gücü) oranı ve çıkış hızına ilişkin en küçük kareler ortalamaları ve standart hataları.

Table 5. The minimum squares averages and standard errors related to the output (strength) ratio and exit speed of lettuce seed of different diameter batch coating.

\begin{tabular}{ccc}
\hline \multirow{2}{*}{ Yöntem } & Çıkış Oranı (\%) & Çıkış Hızı (Gün) \\
\cline { 2 - 3 } & $\mathbf{P}=\mathbf{0 . 0 0 0}$ & $\mathbf{P}=\mathbf{0 . 0 1 5}$ \\
\hline Kontrol & $87.00 \pm 1.264^{\mathrm{a}}$ & $3.53 \pm 0.022^{\mathrm{a}}$ \\
Kapl $^{450}$ & $70.25 \pm 1.264^{\mathrm{b}}$ & $3.64 \pm 0.022^{\mathrm{b}}$ \\
Kapl $^{600}$ & $66.25 \pm 1.264^{\mathrm{b}}$ & $3.56 \pm 0.022^{\mathrm{a}}$ \\
\hline Genel & $\mathbf{7 4 . 5 0} \pm \mathbf{0 . 7 3 0}$ & $\mathbf{3 . 5 7} \pm \mathbf{0 . 0 1 2}$ \\
\hline
\end{tabular}

\section{Sonuç}

Kaplama teknolojileri tohumları hastalık ve zararlılardan üst düzeyde korumasının yanında, ekimde kolaylık ve bitki gelişimine de katkı sağlayan bir teknolojik yararı olan alternatif tekniklerdendir. Tohum kaplama için, farklı özelliklerde makinalardan yararlanılmaktadır. Başarılı bir tohum kaplamada çeşitli unsurlar bulunmakla birlikte, kullanılacak olan makinanın özellikleri de bu unsurlara eklenebilir. Bu çalışmada iki farklı kazan çapına (450-600 mm) sahip olan makine ile marul tohumlarına peletle kaplama uygulaması yapılmıştır. Kaplama sonucunda bazı fiziko-mekanik özellikler ve çimlenme parametreleri bakımından farklılıklar ortaya konulmaya çalışılmıştır. Küresellik, geometrik ortalama çap tohumların ekilişlerinde önemli etkenlerdendir. Çalışmada $450 \mathrm{~mm}$ çaplı kazana sahip olan makine ile kaplamanın, $600 \mathrm{~mm}$ çapa sahip olan kaplamaya göre sirasıyla küresellik (0.79-0.76) ve geometrik ortalama çap (2.95-2.82) değerleri bakımından daha olumlu sonuç verdiği ortaya konulmuştur. Kapl ${ }^{450}$ grubunun genişlik (2.68) ve kalınlık (2.60) bakımından, $\mathrm{Kapl}^{600}$ grubu genişlik (2.54) ve kalınlık (2.43) değerlerine göre önemli düzeyde istatistik olarak anlamlı farklılıklar ortaya koymaktadır.

Ayrıca peletle tohum kaplamada başarı kriterleri açısından, tohumların her bir pelette birer adet olması istenmektedir. Birden çok tohum ya da hiç tohum olmaması fide yetiştiriciliği açisından istenmeyen durumdur. $\mathrm{Bu}$ parametreler incelendiğinde, Kapl ${ }^{450}$ grubunda tek tohum oran1 $\% 97$ olurken, $\mathrm{Kapl}_{1}{ }^{600}$ grubunda ise tek tohum oranı $\% 92$ olmuş ve önemli düzeyde istatistik olarak anlamlı farklılıklar ortaya koymuştur. Öte yandan, fide yetiştiriciliği maliyet, kar, zarar bakımından düşünüldüğünde $\% 4$ 'lük fark ile Kapl ${ }^{450}$ grubunun çimlenme oranları değerleri $(\% 70.25)$ daha yüksek çıkmakta ancak istatistiki olarak önem arz etmemektedir. Marul tohumlarının peletle kaplanmasında $600 \mathrm{~mm}$ yerine $450 \mathrm{~mm}$ olan daha küçük rotor çapına sahip olan makine ile kaplama; tek tohum oluşması, geometrik çap ve küresellik kriterleri açısından daha olumlu sonuçlar ortaya koymaktadır.

\section{Kaynaklar}

Aydin C (2003) Physical properties of almond nut and kernel. Journal of Food Engineering 60: 315-320.

Barut ZB (2006) Kaplanmış susam (Sesamum Indicum L.) tohumlarının tarla koşullarında ekim düzgünlügü. Tarımsal Mekanizasyon 23. Ulusal Kongresi, Çanakkale.

Gerber D (1988) Seed pellets and process for their manufacture. US Patent 4,759,151.

Corlett FMF, Rufino CA, Vieira JF, Tavares LC, Tunes LVM, Barros ACSA (2014) The influence of seed coating on the vigor and early seedling growth of barley. Ciencia e Investigacion Agraria 41(1): 129-136.

Copeland LO, McDonald MB (1995) Seed Science and Technology 3rd edn. New York.

Coşkun MB, Yalçın İ, Özarslan C (2006) Physical Properties of Sweet Corn Seed (Zea mays saccharata Sturt.). Journal of Food Engineering 74(4): 523-528.

Haciyusufoğlu AF (2013) Peletle tohum kaplama ilkeleri. 29. Ulusal Tarımsal Mekanizasyon ve Enerji Kongresi, Diyarbakır.

Haciyusufoglu AF, Erkul A (2015) Arpa tohumuna bitki besin elementli peletle tohum kaplama metodu uygulanmasi, International Journal of Scientific and Technological Reseach 1(6), ISSN 2422-8702 (Online).

Halmer P (2006) Seed technology and seed enhancement. In XXVII International Horticultural Congress-IHC2006: International 
Symposium on Seed Enhancement and Seedling Production 771: 17-26.

ISTA (2013) International Rules for Seed Testing. Seed Science Technologies 21: 1-288.

Kavak S (2006) Bazı polimer kaplama materyal ve uygulamalarının soğan tohumu depo ömrü ve yaşlanma üzerine etkileri. Ege Üniversitesi Fen Bilimleri Enstitüsü, Doktora Tezi, s. 3.

Karakuzu E (2015) Fesleğen (Ocimum basilicum L.) tohumunun ekim olanakları. Adnan Menderes Üniversitesi, Fen Bilimleri Enstitüsü, Yüksek Lisans Tezi.

Mohsenin NN (1978) Physical properties of plant and animal materials. Gordon and Breach Science Publishers, New York, NY.

Nascimento W, Silva J, Marton L (1993) Qualidade fisiológica de sementes peletizadas de tomate durante o armazenamento. Informativo abrates 3: 47.

Olajide JO, Igbeka JC (2003) Some physical properties of groundnut kernels. Journal of Food Engineering 58(2): 201-204.

Rufino CA, Tavares LC, Brunes AP, Lemes ES, Villela FA (2013) Treatment of wheat seed with zinc, fungicide, and polymer seed quality and yield. Journal of Seed Science 35(1), ISSN 2317-1537.

Sarıçam Ş, Kantoğlu YT, Ellialtıoğlu Ş (2018) Kaplı ve kapsız marul (Lactuca sativa var. longifolia cv. Cervantes) tohumlarında etkili mutasyon dozunun belirlenmesi. E-Tralleis Dergisi 3(2): 229-242.
SAS (1999) The SAS System SAS Institute Inc., Cary, NC, USA, Version 8 Copyright (C) 1999.

Sherin SJ (2003) Seed film coating technology using polykote for maximizing the planting value, growth and productivity of maize cv. CO1. Microbiology of Science Agriculture Thesis, Tamil Nadu Agricultural University, Coimbatore, India.

Sikhoa P, Taylor GA, Marino ET, Catranis CM, Siri B (2014) Development of seed agglomeration technology using lettuce and tomato as model vegetable crop seeds. Scientia Horticulturae 184: 85-92.

Taylor AG, Allen PS, Bennett MA, Bardford KJ, Burris JS, Misra MK (1998) Seed Enhancements. Seed Science Research 8(2): 245-256.

Yalçın İ, Özarslan C, Akbaş T (2007) Physical properties of pea (Pisum sativum) seed. Journal of Food Engineering 79(2): 731-735.

Yildız M, Özgen M (2004) The effect of a submersion pretreatment on in vitro explant growth and shoot regeneration from hypocotyls of flax (Linum usitatissimum). Plant Cell, Tissue and Organ Culture 77(1): 111-115. 